\title{
Passive ionospheric radar builds with USRP N210
}

\author{
Luboš Rejfek ${ }^{*}$, Daniel Kouba*, Zbyšek Mošna*, Petra Koucká Knížová*, \\ Phuong T. Tran ${ }^{* *}$, Chau Si-Thien Dong ${ }^{* *}$
}

\begin{abstract}
This paper presents first results and test of passive detection of Digisonde signal obtained at the Průhonice station, Czech Republic. Described technique can be used to analyze signals transmitted by the Digisonde and further received by simple loop antenna. The receiving system is based on the software defined radio (SDR USRP N210). The device works as the two channels receiver. This method will be employed to record oblique ionograms at several locations in the Czech Republic forming a simple array for detection of fine structures within ionospheric plasma using common DPS 4D transmitter. Using relatively inexpensive passive detection helps to increase a number of reflection points which leads to a better spatial coverage of the ionosphere sounding. The device represents a complementary measurement for detection of signal transmitted by Digisondes in European sector.

K e y w or d s: ionogram, digisonde, passive radar, GNU radio, software defined radio
\end{abstract}

\section{Introduction}

The ionosphere is ionized part of the upper atmosphere significantly affecting propagation of electromagnetic signals $[1,2]$. It is highly variable on large range of time scales. Ionosphere is primarily driven by solar activity and geomagnetic activity. The influence from neutral atmosphere at all height span cannot be neglected either [eg 3,4, among others]. Hence, the ionosphere reflects variability on scales of minutes, days, seasons, solar cycles, and even secular changes. The ionosphere strongly influences many modern technological systems as Global Navigation Satellite Systems (GPS, Galileo, Glonass, etc), telecommunication, and other technologies [5].

The ionospheric observatory at Průhonice $\left(50^{\circ} \mathrm{N}\right.$, $14.5^{\circ} \mathrm{E}$ ) is located near Prague, Czech Republic and has operated since 1957 on a regular basis. At present, vertical measurement is provided by the Digisonde DPS4D which records vertical time-frequency characteristics (ionograms) and ionospheric plasma Drift (DDM) [6]. Additionally, GPS receiver and Continuous Doppler Measurement are located in Průhonice that provide ionospheric data $[7,8]$.

\section{Ionospheric measurements}

The principle of ionosonde vertical measurement is vertical transmission of electromagnetic signal (usually at frequencies $1-20 \mathrm{MHz}$ ) and detection of the reflected signal from ionosphere in the antenna system. From time delay between transmission and detection of the reflected signal the so-called virtual height is computed. The transmitted signal can propagate in medium with plasma frequency lower than frequency of the signal, and reflects in point where the plasma frequency of ionospheric plasma and frequency of the signal are equal. Assuming that the signal propagates vertically with the speed of light (which is not generally true) the height of reflection can be computed using equation (2), $h^{\prime}$ represents virtual height, $\Delta s$ are samples between transmitted signal and echo, $c_{0}$ is speed of light in vacuum and $f_{s}$ is sampling frequency. To get true/real height electron density profile inversion techniques must be employed. For the Digisondes we use NHCP inversion algorithm incorporated into the ARTIST/DPS-4D software [9]. The ionograms are automatically scaled and real height is computed by ARTIST. The automatically scaled ionograms are sent to international databases (actual Pruhonice ionograms can be seen on digisonda.ufa.cas.cz). Figure 1 shows typical daily ionogram with traces of E, Es, F1, and F2 layers, in real time. Modern ionosondes (as is the DPS-4D) allow us to distinguish between ordinary and extraordinary modes, which increase quality of interpretation of the measured data. During day-time the E layer and F layer exist (during summer season, the $\mathrm{F}$ layer splits often into F1 and F2 layers)

After sunset, the E layer vanishes due to rapid recombination of ions and ionization remains below observable limits of ionosondes during night-time. Recombination processes within F layer are much slower, hence despite the recombination the $\mathrm{F}$ layer remains observable."

Further, so-called sporadic E layer (Es layer) can be formed at heights of E region, typically during summer months. Sporadic E layers are thin sheets of enhanced

* Department of Aeronomy, Institute of Atmospheric Physics, Czech Academy of Sciences, Czech Republic lre@ufa.cas.cz, kouba@ufa.cas.cz, zbn@ufa.cas.cz, ** Faculty of Electrical and Electronics Engineering, Ton Duc Thang University, Ho Chi Minh City, Vietnam, tranthanhphuong@tdtu.edu.vn, dongsithienchau@tdtu.edu.vn 


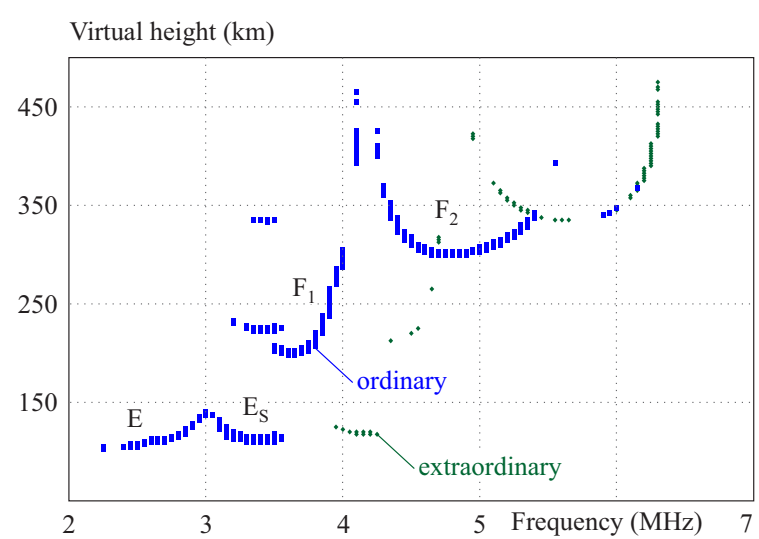

Fig. 1. Ionogram measured at the observatory Průhonice (Day: 11.7.2018, Time: 8:15 UT) with detected ordinary and extraordinary modes of reflection

electron concentration located in the height of ionospheric E region. The maximum plasma frequency of the Es layer (critical frequency $f_{\mathrm{o} E \mathrm{~s}}$ ) often exceeds the E, or even $\mathrm{F}$ layer plasma frequencies $\left(f_{\mathrm{o}} E, f_{\mathrm{o}} F_{2}\right)$ which leads to a significant role of Es layers in propagation of electromagnetic signals (Fig. 1). Sometimes, the reflection from Es completely blocks an upper laying layer which leads to a situation called complete blanketing (Fig. 9). Typical time resolution of measurement of the Digisonde in Průhonice is $15 \mathrm{~min}$, although this value can be reduced up to $1 \mathrm{~min}$ for special campaigns [10]. The relation between $f_{N}$ and $N_{e}$ can be written as

$$
f_{N}^{2}=\frac{N_{e} e^{2}}{\varepsilon_{0} m},
$$

where $f_{N}$ is the plasma frequency, and $e, N_{e}, \varepsilon_{0}$ and $m$ are electron charge, maximum electron concentration, permittivity of vacuum and mass of the electron, respectively [1]. Usually, the highest critical frequency is located in the F2 region.v The virtual height $h^{\prime}=t c / 2$ where $t$ is the time-of-flight of the transmitted and received signal, and $c$ is speed of light.

A passive receiver using the same HW (USRP N210, loop antennas and main computer) has been introduced by Vierinen for high latitude ionospheric sounding. The system has been defined for the monitoring of the Alphawolf ionosonde.

\section{Observatory Průhonice}

The ionospheric station Průhonice was established during International Geophysical Year in 1957-1958. First equipment, used at the station, was a Russian ana$\log$ ionosonde AIS. Its antenna system consisted of two $26 \mathrm{~m}$ high rhombic transmitting/receiving antennas. The ionosonde provided vertical ionospheric sounding (measured ionograms) with 15 minutes cadence at sounding frequencies $1-16 \mathrm{MHz}$.

In 1984, the Russian ionosonde AIS was replaced by the Australian ionosonde IPS-42. The existing rhombic antenna was used as a transmitting antenna. Additional
$36 \mathrm{~m}$ height double delta antenna was built as a receiving antenna. The ionosonde recorded ionograms typically with 15 minutes cadence in the frequency range $1-22.6 \mathrm{MHz}$. The ionosonde IPS-42 operated in the observatory till early January 2004.

In January 2004, a new digital ionosonde DPS-4 (Digisonde) developed by the University of Massachusetts Lowell, Center for Atmospheric Research (UMLCAR) was installed in the observatory. The Digisonde operates with four cross-loop receiving antennas. An ionogram auto scaling process ARTIST [11] automatically finds standard ionospheric characteristics. In addition to the vertical ionogram sounding, drift measurements are performed in both $\mathrm{F}$ and $\mathrm{E}$ regions. Data and auto scaled characteristics are distributed to the data centers and presented in real-time on web.

In January 2010 the Digisonde was upgraded to version DPS-4D. The Digisonde DPS-4D is the digital ionosonde developed during 2004-2008 by UMLCAR and allows a wide range of new possibilities for ionospheric measurements. The new letter D refers to the digital transmitters and receivers in the DPS- $4 \mathrm{D}$ that implement the classic functions of radio transmitters and receivers by numeric techniques. It applies also new software solutions for data acquisition, hardware control, user commanding and data processing [12]. Novelty of the system lays in the possibility of a wide range of programs and schedules. DPS-4D can work in PGH mode (Precision Group Height) with precise detection of reflection height.

\section{Digisonde Portable Sounder 4D (DPS-4D)}

The Digisonde DPS-4D operates up to 256 specific measurement programs defined by user in the DCART software. It serves to manage the operational parameters and measurement regimes for all individual programs.

The basic programs consist of ionogram sounding, drift measurements, passive RF sounding mode, and D2D (Digisonde to Digisonde) measurements. The measurement parameters are programmed in the DCART software for each program. Practically, sounding frequency window, frequency step, number of pulses per frequency, and other parameters are defined. Sounding frequency is a key parameter for drift measurements, and coherent integration time (CIT) is a significant parameter for drift measurements also. The D2D measurement is sounding performed between two Digisondes: transmitting (operates in active mode) and receiving (in passive mode). It is necessary to choose the same settings (especially sounding frequency and time of measurement) for both stations. Details and practical examples for all sounding modes are described in "Digisonde technical manual", [13-15].

Sequence of measurement programs is defined in Schedule. The measurement programs defined in the Schedule are started automatically in the endless loop. Typical schedule duration is 15 minutes. However, it is possible to realize for example high-cadence campaigns with 1-minute loop. 


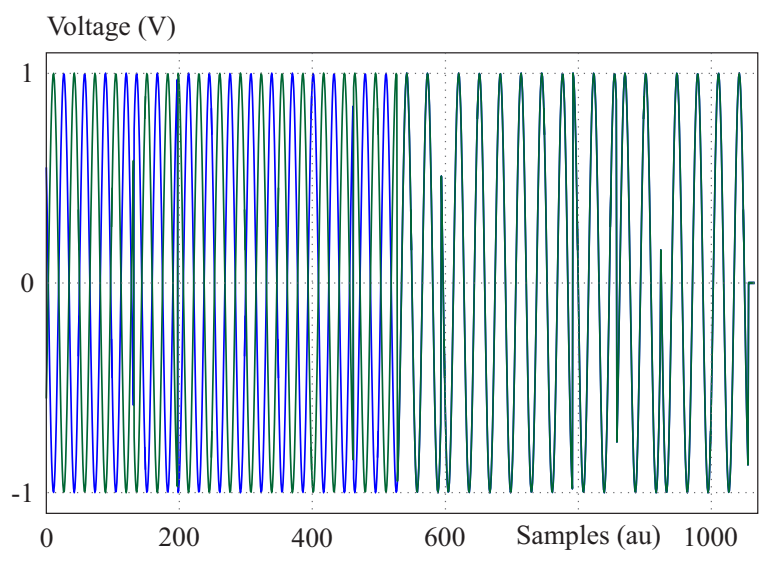

Fig. 2. Example of the signals transmitted by the Digisonde (coded

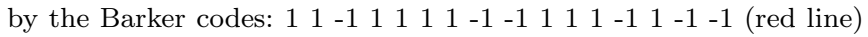

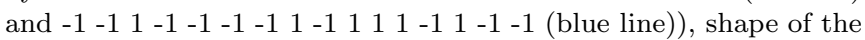
received signal will be function of the frequency and phase.

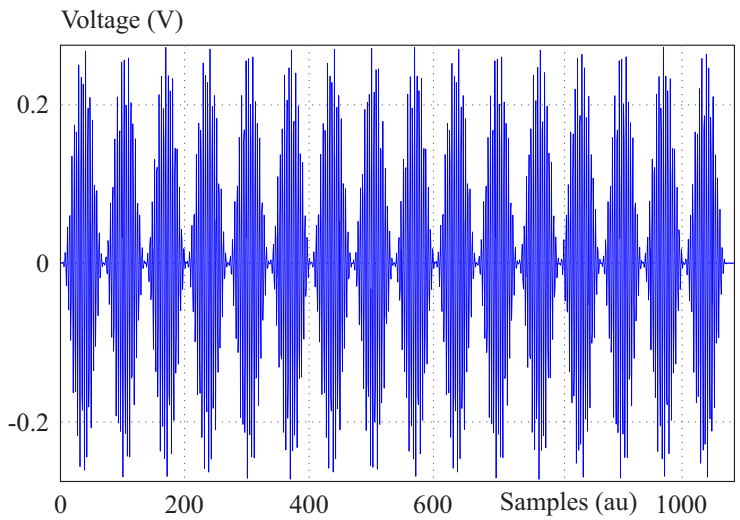

Fig. 4. Real received signal from the Digisonde measured at the observatory Průhonice by developed device, 23 May 2018. Zoomed on the received signal, this signal is coded by the Barker code with 16 pulses.

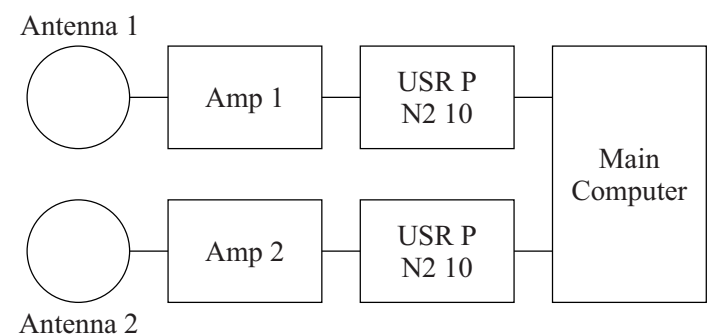

Fig. 5. HW connection of the proposed device

During typical 15-minutes Schedule is realized one ionogram sounding, drift measurements for $\mathrm{F}$ and $\mathrm{E}$ region and several D2D measurements. It is effective to use different schedules for daytime and night-time. Especially ionogram sounding can be applied in narrower

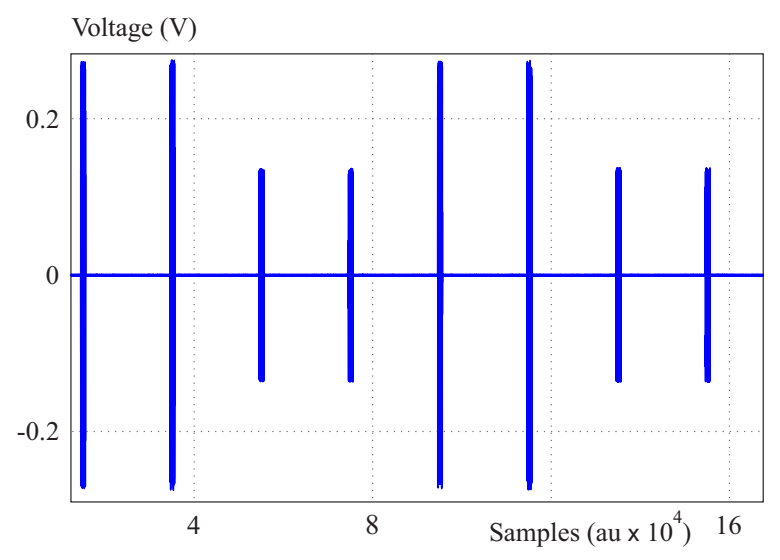

Fig. 3. Real received signal from the Digisonde measured at the observatory Průhonice by developed device, 23 May 2018. Every frequency is measured twice

frequency window according to typically lower critical frequency foF2 during night-time. Also drift measurements for the E-region are superfluous during night-time.

\section{Technical parameters}

Digisonde transmits signals coded by the Barker codes. In our case, the used codes are composed from the 16 bits. We use one identical code for all transmitting antenna. Examples of the used Barker codes are shown in Fig. 2. Shape of these pulses depend on the transmitted frequency. Number of repetitions of every measurement can be set from the list. At the Pruhonice observatory, we repeat the measurement twice. The step can be adjusted too. In case of Průhonice observatory, we use step equal to $50 \mathrm{kHz}$. Example of the Digisonde signal is shown in Fig. 3. On the zoomed signal, shown at Fig. 4, it is possible to see 16 pulses (modulation by Barker codes). Hence, it is evident, that for the sounder we must know the setting of the Digisonde for the application of the sounder which is proposed below.

\section{Description of the proposed device}

Our system is based on the software defined radio (SDR USRP N210). The device operates as the two channels receiver. Both channels are composed of the antenna, amplifier and software defined radio. Both channels are connected to main computer. Connection is shown in Fig. 5. Firmware for the channels is shown in Fig. 6. In SDR central frequency is set for the actually measured band (frequency is $f_{x}+B / 2$ ). SDR oscillator is controlled by GPS receiver. In the next step the signal is filtered

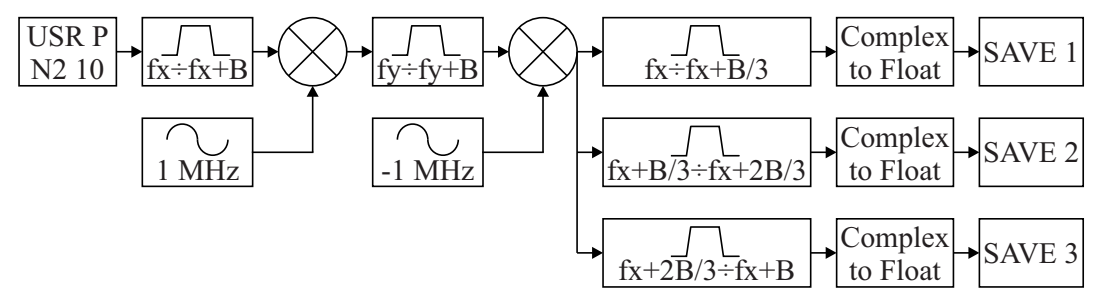

Fig. 6. Block diagram for the primary signal processing and saving of the data 


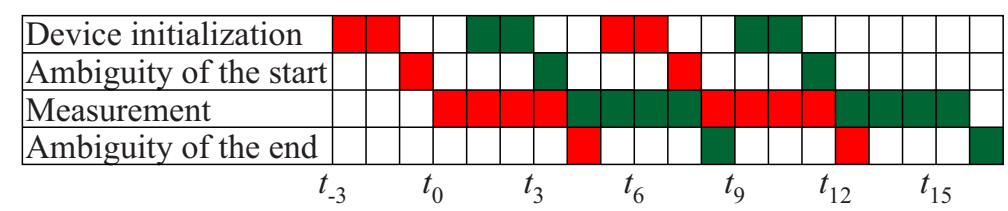

Fig. 7. Timing diagram of channels control

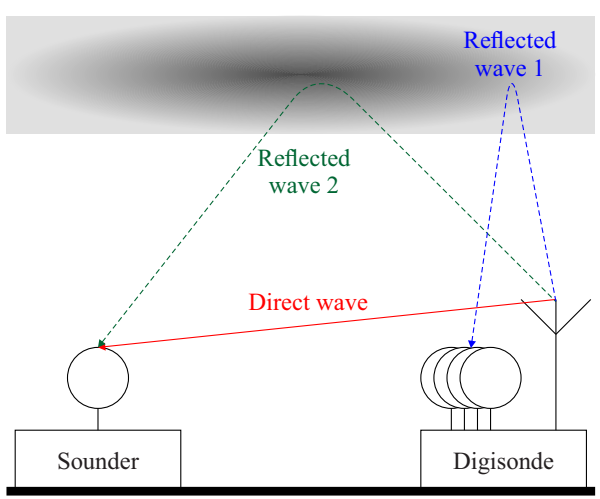

Fig. 8. Description of the experiment

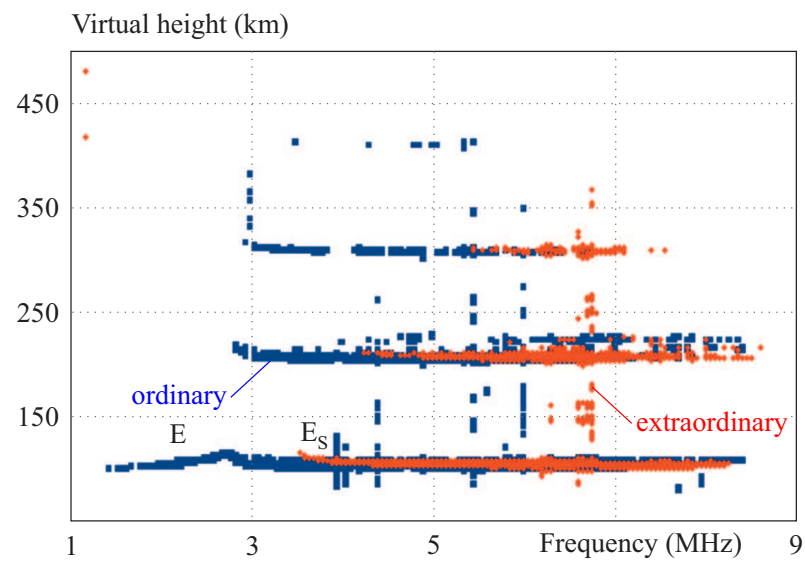

Fig. 9. Example of ionograms measured during the experiment at the observatory Průhonice

by band pass filter. This signal is mixed by $1 \mathrm{MHz}$ and signal on the intermediate frequency is filtered by band pass filter too (it is used for cancellation of the imaginary part of the spectrum). In the next step, the signal is transferred back to base frequency band. Consequently, the signal is separated to three ways and every part is filtered before saving the data. Connection with the main computer is realized by $1 \mathrm{GBit} / \mathrm{s}$ Ethernet. Separation of the signal to the three ways is used for the improvement of the signal noise ratio (SNR) which leads to SNR increase by $4.77 \mathrm{~dB} S N R=P_{S} /\left(2 B N_{0} / 2\right)$. Here $N_{0} / 2$ is power of spectral density (real and imaginary part of the spectrum), $N_{0}$ is Boltzmann's constant multiplied by temperature in Kelvins, $B$ is the bandwidth and $P_{\mathrm{S}}$ is signal power.

Driving of the system is realized according to Fig. 7 . Color red represents the first channel and color green represents the second channel. The first line in the graph represents switching on of the devices. The second and the fourth line are reserves for small errors in the synchronization. The third line represents the measurement part which will be used for the analysis. Starting time is set before start of the measurement of the ionogram, because through start time of the measurement the device records the signal. The dual channel system was chosen because we need recording the data in the sequences. Too long data set could not be processed in many SW and if we are recording whole measurement, we have to use very big sampling frequency (due to the Nyquist theorem), but when we are using shorter sequences we can change the central frequency for the first mixing in the SDR and we can use smaller sampling frequency for the recording of the signal.

\section{Test of the proposed device}

Proposed device was tested at the observatory Průhonice (the sounder was placed near the Digisonde). Principle of the experiment is shown in the Fig. 8. Blue curve represents measurement of the ionogram by the Digisonde. Green curve represents propagation of the signal from the Digisonde to the sounder with signal reflection in the ionosphere. Red line represents direct wave. This wave will be used for the synchronization of the devices. Digisonde has dual transmitting antenna, which allows transmission of two pulses with different coding in one time. Receivers are connected with antenna array. Due to four receiving antennas, Digisonde can measure incoming angles of the signal. In contrary, our device has only one antenna and cannot measure incoming angles of reflected signal.

\section{Results}

The test of the device was performed on 23 May 2018. The ionogram from the measurement is shown in Fig. 9. Due to presence of strong Es layer we could not observe upper laying layers F1 and F2. The next information is that the signal has more reflections through propagation. This ionogram is ideal for the test, because the virtual height for all transmitted frequencies is approximately the same and the predicted height around $100 \mathrm{~km}$ can be used for the verification of the results. Main disadvantage of our device is that it cannot typically distinguish the ordinary and the extraordinary reflections ( $e g$ we cannot distinguish between ordinary and extraordinary modes in Fig. 9 using the device).

Figure 10 compares the signals without final filtration (green line) and two cases with this filtration (blue line for the second way and red line for the third way) are shown. From the figure we see that filtered signals are delayed 


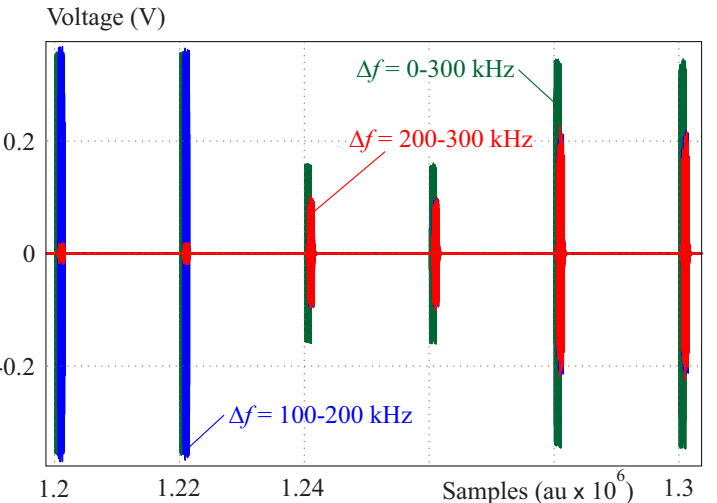

Fig. 10. Influence of the signal processing on the received data

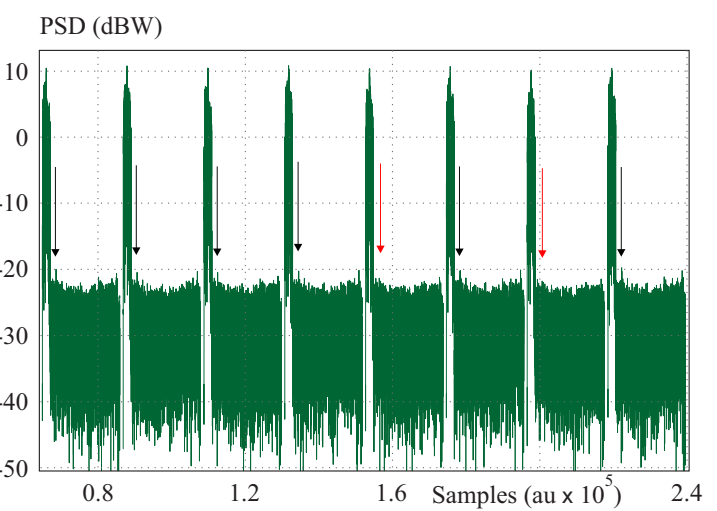

Fig. 12. The series of the measured data after correlation. Black and red arrows denote correctly and incorrectly detected echoes, respectively

compared to non-filtered signal, but the processing way is same for the direct and reflected signal. However, if we want to use only reflected signal (long distance transmission) and synchronization is made only by the GPS receivers, we must include this influence for the signal processing. In Fig. 10 it is possible to see the band pass filter influence. As the windows are not rectangular, we can see transient characteristics (place where red and blue lines have the same amplitude).

Examples of the data evaluation are shown in Fig. 13. The used process was thresholding, where the signals smaller than the threshold value were removed (set on the value $-70 \mathrm{dBW})$. Peaks of the reflected and direct signals were marked. We can see that the distance between the peaks in the first case is 2613 samples and in the second case 3077 samples. The sampling frequency was

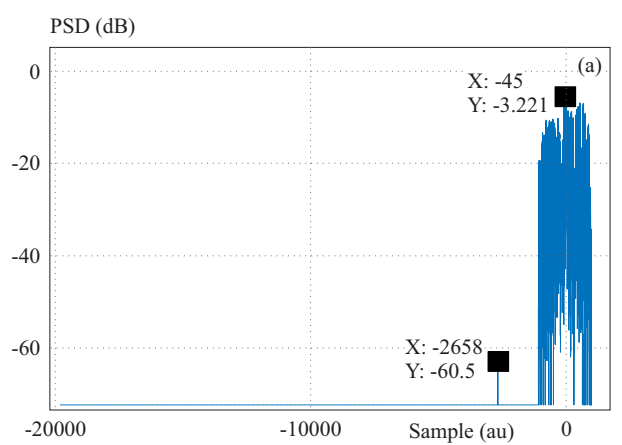

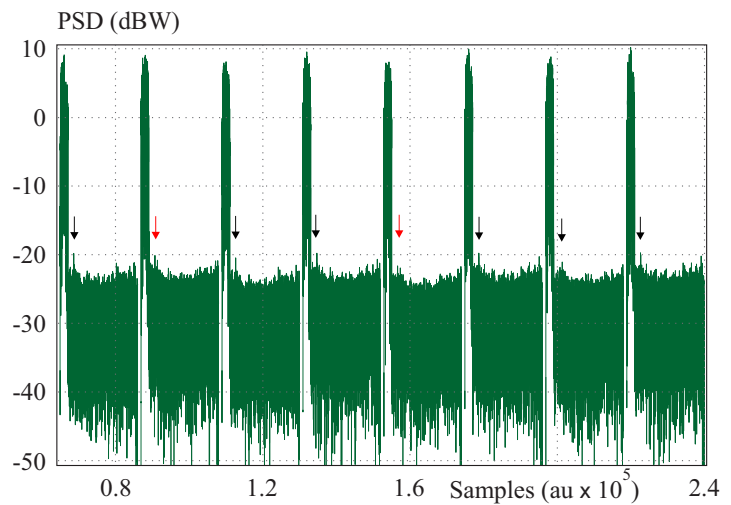

Fig. 11. The phase influence on correlation between the expected signal and the received signal. (The arrows represent position of the echoes

$4 \mathrm{MHz}$. The virtual height $h^{\prime}=t c / 2=98 \mathrm{~km}$ for the first case and $115 \mathrm{~km}$ for the second case. The Digisonde ionogram connected to the analyzed case shows that the distances (height of the ionosphere) correspond to the expected heights of the Es layer.

\section{Conclusion}

In this article we described the device for the passive measurement of the ionosphere for obtaining of vertical or oblique ionograms. Using this device we can increase number of ionograms describing the ionosphere between the transmitter and the receiving antenna which means better spatial description of the ionosphere. This is useful $e g$ for the monitoring of the traveling ionospheric disturbance (TID) waves. The device will be used for complementary measurements for detection of signal transmitted by Digisondes in European sector.

The device was tested on-site and from the results we conclude that it can be used for the planned application. Currently, it is necessary to finalize the data manually. Future work will deal with automatic generation of the ionograms. Several problems have been discussed in the paper, eg signal propagation delay in the filters, which will be important after increasing of the distance between Digisonde and sounder, or complications caused by the phase shifts. Our experience will be used during the future work on the project.

In the future we are planning to implement full automatic derivation of the ionogram from the received data

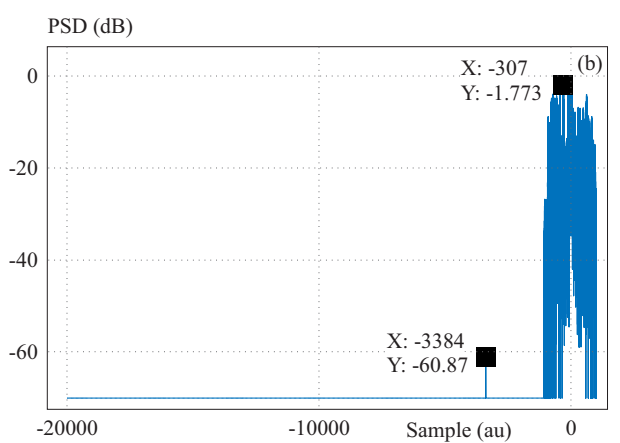

Fig. 13. The examples of the obtained results after thresholding 
and description of the parameters like critical frequencies, virtual heights, and total electron content (TEC).

Acknowledgements

This study was supported by grant EC H2020-COMPET2017 TechTIDE project, No. 776011.

\section{REFERENCES}

[1] F. F. Chen, "Introduction to Plasma Physics", New York: Plenum Press, 1974.

[2] K. Davies, "Ionospheric Radio", Peter Peregrinus Ltd, London, 1990.

[3] K. Georgieva, B. Kirov, and E. Gavruseva, "Geoeffectiveness of Diferent Solar Drivers, Long-Term Variations of the Correlation between Sunspot Geomagnetic Activity", Physics Chemistry of the Earth, vol. 31, pp. 81-87, 2006.

[4] J. Laštovička, "Forcing of the Ionosphere by Waves from Below", Journal of Atmospheric Solar-Terrestrial Physiscs vol. 68, pp. 479-497, 2006

[5] A. Belehaki, L. Cander, B. Zolesi, J. Bremer, C. Juren, I. Stanislawska, D. Dialetis, and M. Hatzopoulos, "Ionospheric Specification Forecasting Based on Observations from European Ionosondes Participating in DIAS Project", Acta Geophysica vol. 55, no. 3, pp. 398-409, 2007.

[6] B. W. Reinisch, X. Huang, I. A. Galkin, V. Paznukhov, and A. Kozlov, "Recent Advances in Real-Time Analysis of Ionograms Ionospheric Drift Measurements with Digisondes", Journal of Atmospheric Solar Terrestrial Physics, vol. 67, pp. 1054-1062, 2005.

[7] D. Buresova, J. Lastovicka, and G. De Franceschi, "Manifestation of Strong Geomagnetic Storms in the Ionosphere above Europe", Space Weather, Springer, pp. 185-202, 2007.

[8] J. Chum, F. Bonomi, J. Fiser, M. Cabrera, R. Ezquer, D. Buresova, J. Lastovicka, J. Base, F. Hruska, and M. Molina, Propagation of Gravity Waves Spread F in the Low-Latitude Ionosphere over Tucuman, Argentina, by Continuous Doppler Sounding: First Results", Journal of Geophysical Research: Space Physics vol. 119 no. 8, pp. 6954-6965, 2014.

[9] X. Huang and B. W. Reinisch, "Vertical Electron Density Profiles from the Digisonde Network", Advances in Space Research vol. 18, no. 6, pp. 121-129, 1996.

[10] P. Šauli, Z. Mošna, J. Boška, D. Kouba, J. Latovička, and D. Altadill, "Detection of the Wave-Like Structures in the F-Region Electron Density: Two Station Measurements", Studia Geophysica et Geodaetica, pp. 131-146, 2006.

[11] I. A. Galkin, G. M. Khmyrov, A. V. Kozlov, B. W. Reinisch, X. Huang and V. V. Paznukhov, "The ARTIST 5", in Radio Sounding Plasma Physics, AIP Conf, Proc, 974, pp. 150-159, 2008 .

[12] B. W. Reinisch, I. A. Galkin, G. M. Khmyrov, A. V. Kozlov, I. A. Lisysyan, K. Bibl, G. Cheney, D. Kitrosser, S. Stelmash, K. Roche, Y. Luo, V. V. Paznukhov and R. Hamel, "Advancing Digisonde Technology: the DPS-4D," in Radio Sounding Plasma Physics, AIP Conf, Proc, 974, pp. 127-143, 2008.

[13] I. A. Galkin and B. W. Reinisch, "The new ARTIST 5 for All Digisondes," Ionosonde Network Advisory Group Bulletin, vol. 69 , no. 8 .

[14] T. Verhulst Altadill et al, "Vertical Oblique HF Sounding with a Network of Synchronised Ionosondes", Advances in Space Research vol. 60, no. 8, pp. 1644-1656, 2017.

[15] B. W. Reinisch and I. A. Galkin et al, "New Digisonde for Research Monitoring Applications", in Radio Science vol. 44, no, 01, pp, 1-15, Feb 2009, doi:10.1029/2008RS004115keywords: http://ieeexplore.ieee.org/stamp/stamp.jsp?tp=\&arnumber $=$ $7775865 \&$ isnumber $=7771653$.
[16] J. G. Proakis, "Digital Communications, Chapter 5", 4th Ed, , McGraw-Hill, 2001.

Received 11 Decenber 2018

Luboš Rejfek was born in 1985 in Chrudim, Czechoslovakia, graduated ( $\mathrm{PhD}$ degree) in 2017 at the Department of Electrical engineering of the Faculty of Electrical Engineering and Informatics at the University of Pardubice. At present he is assistant professor at the same department and he is employed at the Institute of Atmospheric Physic of the Czech Academy of Sciences.

Zbyšek Mošna was born in 1978 in Prague. He defended his $\mathrm{PhD}$ in 2014 at the Faculty of Mathematics and Physics of the Charles University in Prague. He is engaged in the field of ionospheric variability, vertical coupling and effects of solar, geomagnetic, and neutral atmosphere activity into the ionosphere. He works at the Institute of Atmospheric Physics of the Czech Academy of Sciences.

Daniel Kouba was born in 1975 in Chomutov, Czechoslovakia. He graduated (Master degree) in 1999 at the Department of Geophysics of the Faculty of Mathematics and Physics at the Charles University in Prague and completed his doctoral degree $(\mathrm{PhD})$ in 2014 at the Department of Surface and Plasma Science. He is employed at the Institute of Atmospheric Physics of the Czech Academy of Sciences. In 2008 he achieved the Young Scientists Award (URSI / International Union of Radio Science).

Petra Koucká Knížová was born in 1972 in Prague. She defended her PhD in 2002 at the Faculty of Mathematics and Physics of the Charles University in Prague. Her primary interest is ionospheric variability, especially the wave-like variations in the ionospheric plasma and vertical coupling process in the neutral atmosphere-ionosphere system. She has received Otto Wichterle Award for young scientist in 2007, and award LOreal for Women in Science in 2008. She works at the Institute of Atmospheric Physics of the Czech Academy of Sciences.

Phuong Thanh Tran was born in 1979 in Ho Chi Minh City, Vietnam. He received BEng and MEng degrees in Electrical Engineering from Ho Chi Minh University of Technology, Ho Chi Minh City, Vietnam in 2002 and 2005, respectively. In 2007, he became a Vietnam Education Foundation Fellow at Purdue University, USA, where he received his PhD degree in Electrical and Computer Engineering in 2013. In 2013, he joined the Faculty of Electrical and Electronics Engineering of Ton Duc Thang University, Vietnam and served as the Vice Dean of Faculty since October 2014. His major interests are in the area of wireless communications, network information theory and digital signal processing.

Chau Si-Thien Dong was born in 1978 in Ho Chi Minh City, Vietnam. She received BEng and MEng degrees in Electrical Engineering from Ho Chi Minh University of Technology, Ho Chi Minh City, Vietnam in 2001 and 2003, respectively. In 2014, she attended the sandwich program between Ton Duc Thang University, Vietnam and VSB Technical University of Ostrava, Czech Republic and received her PhD degree in Electrical Machines in 2018. She has been working in the Faculty of Electrical and Electronics Engineering of Ton Duc Thang University, Vietnam since 2001 and has been the Dean of the Faculty since May 2018. Her major interests are in the area of nonlinear control, robust control, electrical drive and neural network. 